\title{
Poor outcome of octogenarians admitted to ICU due to periprosthetic joint infections: a retrospective cohort study
}

Emre Yilmaz ${ }^{1 *}$ D, Alexandra Poell ${ }^{1}$, Hinnerk Baecker ${ }^{1}$, Sven $_{\text {Frieler }}{ }^{1}$, Christian Waydhas $^{1,2}$,

Thomas A. Schildhauer ${ }^{1}$ and Uwe Hamsen ${ }^{1}$

\begin{abstract}
Background: Even though surgical techniques and implants have evolved, periprosthetic joint infection (PJI) remains a serious complication leading to poor postoperative outcome and a high mortality. The literature is lacking in studies reporting the mortality of very elderly patients with periprosthetic joint infections, especially in cases when an intensive care unit (ICU) treatment was necessary. We therefore present the first study analyzing patients with an age 80 and higher suffering from a periprosthetic joint infection who had to be admitted to the ICU.
\end{abstract}

Methods: All patients aged 80 and higher who suffered from a PJI (acute and chronic) after THR or TKR and who have been admitted to the ICU have been included in this retrospective, observational, single-center study.

Results: A total of 57 patients met the inclusion criteria. The cohort consisted of 24 males and 33 females with a mean age of 84.49 ( \pm 4.0) years. The mean SAPS II score was $27.05( \pm 15.7)$, the mean CCI was $3.35( \pm 2.28)$ and the most patient had an ASA score of 3 or higher. The PJI was located at the hip in $71.9 \%$ or at the knee in $24.6 \%$. Two patients (3.5\%) suffered from a PJI at both locations. Sixteen patients did not survive the ICU stay. Non-survivors showed significantly higher CCI (4.94 vs. $2.73 ; p=0.02$ ), higher SAPS II score (34.06 vs. 24.32; $p=0.03$ ), significant more patients who underwent an invasive ventilation (132.7 vs. $28.1 ; p=0.006)$ and significantly more patients who needed RRT (4.9\% vs. 50\%; $p<0.001$ ). In multivariate analysis, RRT (odds ratio (OR) 15.4, Cl 1.69-140.85; $p=0.015$ ), invasive ventilation (OR 9.6, Cl 1.28-71.9; $p=0.028)$ and $\mathrm{CCl}(\mathrm{OR} 1.5, \mathrm{Cl} 1.004-2.12 ; p=0.048)$ were independent risk factors for mortality.

Conclusion: Very elderly patients with PJI who needs to be admitted to the ICU are at risk to suffer from a poor outcome. Several risk factors including a chronic infection, high SAPS II Score, high CCl, invasive ventilation and RRT might be associated with a poor outcome.

Keywords: Periprosthetic joint infection; infection, Intensive care unit, Elderly, Octogenarions

\footnotetext{
* Correspondence: emre.yilmaz@gmx.de

'Department of General and Trauma Surgery, BG University Hospital

Bergmannsheil, Ruhr University Bochum, Bürkle-de-la-Camp-Platz 1, 44789

Bochum, Germany

Full list of author information is available at the end of the article
}

(c) The Author(s). 2020 Open Access This article is licensed under a Creative Commons Attribution 4.0 International License, which permits use, sharing, adaptation, distribution and reproduction in any medium or format, as long as you give appropriate credit to the original author(s) and the source, provide a link to the Creative Commons licence, and indicate if changes were made. The images or other third party material in this article are included in the article's Creative Commons licence, unless indicated otherwise in a credit line to the material. If material is not included in the article's Creative Commons licence and your intended use is not permitted by statutory regulation or exceeds the permitted use, you will need to obtain permission directly from the copyright holder. To view a copy of this licence, visit http://creativecommons.org/licenses/by/4.0/. The Creative Commons Public Domain Dedication waiver (http://creativecommons.org/publicdomain/zero/1.0/) applies to the data made available in this article, unless otherwise stated in a credit line to the data. 


\section{Background}

The term "silver tsunami" describes the progressively ageing population in developed countries and the huge socioeconomic shift that is expected to effect various clinical fields including the „rise and burden of hip and knee osteoarthritis "[1]. According to Kiadaliri et al. the number of prevalent osteoarthritis cases increased by 43\% between 1990 and 2015. The number of knee osteoarthritis alone has doubled in prevalences since the mid-twentieth century [2]. Thus, the estimated prevalence of Total Hip (THR) and Total Knee Replacements (TKR) in the United States was $2,552,815$ and 4,700,621 respectively in 2010. Out of these 640,740 (THR) and 1,087,400 (TKR) were at the age of 80 and higher [3].

Knee and hip arthroplasty are a succesful treatment for osteoarthritis in terms of pain relief, function recovery and enhancing life quality [4,5]. Even though surgical techniques and implants have evolved, periprosthetic joint infection (PJI) remains a serious complication leading to poor postoperative outcome and a high mortality [6]. The incidence of PJI after total joint arthroplasty differs according to localization and type between 1 and 3\% [7]. Up to now, there is no gold standard treatment for patients with PJI. In addition to the Musculoskeletal Infection Society (MSIS) criteria introduced by the American Academy of Orthopedic Surgeons (AAOS) in 2011 [8, 9], the concept of Trampuz and Zimmerli is well known in Europe [10, 11]. Furthermore, treatment of PJI often includes a prolonged hospital stay, multiple surgeries, prolonged antimicrobial treatment, protheses and medical supplies which can lead to a 24 times higher treatment cost $[12,13]$. Several different risk factors have been described for PJI after Total Joint Arthroplasty including obesity, urinary tract infection, diabetes and rheumatoid arthritis [6]. However, the literature is conflicted when it comes to determine age as an independent risk factor. In developed countries the proportion of elderly patients admitted to the Intensive Care Unit (ICU) increased dramatically $[14,15]$. The literature is lacking in studies reporting the mortality of very elderly patients with periprosthetic joint infections, especially in cases when an ICU treatment was necessary. We therefore present the first study analyzing patients with an age 80 and higher suffering from a periprosthetic joint infection who had to be admitted to the ICU.

\section{Methods}

The study has been approved by the local Ethical Committee (No. of approval 18-6260-BR). From January 2012 and December 2016, all patients aged 80 and higher who suffered from a PJI (acute and chronic according to the definition as described by $\mathrm{Li}$ et al. [16]) after THR or TKR and who have been admitted to the ICU have been included in this retrospective, observational, single-center study. In defining periprosthetic joint infection all patients fullfilled criteria according to the European Bone and Joint Infection Society (EBJIS) and Musculoskeletal Infection Society (Table 1) [8, 9, 17]. The ICU consisted of 13bed surgical intensive care unit in a Level 1 university and referral hospital for PJI in Germany. The ICU is accompanied by a stand-alone Intermediate Care Unit (IMC). The IMC ressourses and therapeutic options include an intensivist-led $24 \mathrm{~h}$ presence of a resident experienced in intensive care, monitoring corresponding to ICU-standard, non-invasive ventilation and continuous vasopressor-administration. Therefore, most surgical patients suffering PJI at risk or not stable enough for normal ward are admitted to the IMC. Severity of illness were assessed using the Simplified Acute Physiology Score II (SAPS II) [18], the American Society of Anaesthesiologists Score (ASA) [19] and the Charlson Comorbidity Index (CCI) [20].

Table 1 Definition of Periprosthetic Joint Infections according to the EBJIS criteria and Musculoskeletal Infection Society
EBJIS criteria
I Clinical: sinus tract (fistula) or purulence around prosthesis
II Cell count in joint aspiration: > 2000/ul leukocytes or $>70 \%$ polymorphonuclear granulocytes (PMN)
III Histology: inflammation in periprosthetic tissue (type 2 or 3 after Krenn Morawietz)
IV Microbial growth in synovial fluid or $>=2$ tissue samples (in cases of high virulent microbes like Staphylococcus aureus one sample is considered sufficient) or sonication fluid $\geq 50$ CFU/ml
A PJI is diagnosed if at least one of the following criteria is fullfilled

Musculoskeletal Infection Society criteria

Definition of Periprosthetic Join Infection According to the International Consensus Group. This Is An Adaptation of the Musculoskeletal Infection Society Definition of PJI.

PJI Is Present When One of the Major Criteria Exists or Three Out of Five Minor Criteria Exist

\section{Major Criteria}

Two positive periprosthetic cultures with phenotypically identical organisms, OR

A sinus tract communicating with the joint, OR

\section{Minor Criteria}

1) Elevated serum C-reactive protein (CRP) AND erythrocyte sedimentation rate (ESR)

2) Elevated synovial fluid white blood cell (WBC) count $O R++$ change on leukocyte esterase test strip

3) Elevated synovial fluid polymorphonuclear neutrophil percentage (PMN\%)

4) Positive histological analysis of periprosthetic tissue

5) A single positive culture 


\section{Statistical analysis}

Data were analyzed using SPSS version 21.0 (SSPS Inc., Chicago, IL) and Excel version 16.16.7 (Microsoft Corporation, Redmond, WA, USA). Univariate analysis was performed to compare demographics, surgical characteristics, and intensive care treatment. For categorical variables, frequency counts were computed and presented along with their percentages. For continuous variables, means were computed and presented along with their range. Mann Whitney U-test or Student's T-Test were used, as appropriate. Statistical significance was set at $p<0.05$. Multivariate analysis (binary logistic) was performed using the four most significant parameters in univariate analysis to determine independent risk factors for mortality.

\section{Results}

A total of 57 patients met the inclusion criteria. The cohort consisted of 24 males and 33 females with a mean age of $84.49( \pm 4.0)$ years. The mean SAPS II score was 27.05 ( \pm 15.7), the mean CCI was 3.35 ( \pm 2.28) and the most patient had an ASA score of 3 or higher. The PJI was located at the hip in $71.9 \%$ or at the knee in $24.6 \%$. Two patients (3.5\%) suffered from a PJI at both locations. Most patients suffered from a chronic infection (86\%) and underwent a planned surgical intervention (50.9\%). The results are summarized in Tables 2, 3, 4.

Sixteen patients did not survive the ICU stay. In univariate analysis, non-survivors showed significantly higher CCI (4.94 vs. 2.73; $p=0.02)$, higher SAPS II score (34.06 vs. 24.32; $p=0.03$ ), significant more patients who underwent an invasive ventilation (132.7 vs. $28.1 ; p=$ $0.006)$ and significantly more patients who needed renal replacement therapy (RRT) $(4.9 \%$ vs. $50 \%$; $p<0.001)$. Results are summarized in Table 5 . In multivariate analysis, RRT (odds ratio (OR) 15.4, CI 1.69-140.85; $p=0.015$ ), invasive ventilation (OR 9.6, CI 1.28-71.9; $p=0.028$ ) and

Table 2 Patient demographics are summarized in Table 2

\begin{tabular}{ll} 
& $\begin{array}{l}n=57 \\
(\text { Mean } \pm \text { SD) } \\
n(\%)\end{array}$ \\
\hline Baseline Factors & \\
Age (years) & $84.49 \pm 4.0$ \\
Sex (male) & $24(42.1 \%)$ \\
BMI* & $26.70 \pm 5.25$ \\
SAPS II* & $27.05 \pm 15.7$ \\
CCI* & $3.35 \pm 2.28$ \\
ASA Score* & $3.09 \pm 0.58$ \\
ASA Score $\geq 3^{*}$ & $40(87.8 \%)$ \\
\hline
\end{tabular}

*SAPS II Simplified Acute Physiology Score II; CCI Charlson Comorbidity Index; ASA American Society of Anaesthesiologists Score; BMI Body mass index
CCI (OR 1.5, CI 1.004-2.12; $p=0.048)$ were independent risk factors for mortality (Table 6).

\section{Discussion}

This study presents the first study ever to analyze the outcome of octagenarions in the setting of PJI and ICU treatment. PJI is a devastating complication resulting in severe pain, functional impairment and high mortality [21]. Furthermore, the estimated costs for infection revision is expected to be as high as $\$$ 1.62 billion in the United States alone [22]. A validated risk score to assess and predict PJI does not exist. However, several risk factors have been discussed in the setting of PJI. Zuh et al. reported in their systematic review that body mass index, diabetes mellitus, corticosteroid therapy; hypoalbuminaemia, rheumatoid arthritis, blood transfusion, presence of a wound drain, wound dehiscence, superficial surgical site infection, coagulopathy, malignancy, immunodepression, National Nosocomial Infections Surveillance (NNIS) score $\geq 2$, prolonged operative time and previous surgery are potential risk factors for PJI [23].

Even though most of these factors were not analyzed in detail in our study the vast majority of our patients had an ASA score of 3 and higher. Maaloum et al. reported a mortality rate of $20 \%$ in their retrospective case series analyzing 41 patients (mean age: $71.8 \pm 9.4$ years) suffering from a PJI admitted to the ICU. They could show as well that a high SAPS II score and a high ASA score is associated with a high mortality rate [24]. We also observed a significantly higher CCI in non-survivors compared to patients who have survived $(4.94 \pm 2.14$ vs. $2.73 \pm 2.04 ; p=0.02$ ). The proportion of patients requiring a RRT $(50 \%$ vs. $4.9 \% ; p<0001)$ or invasive ventilation ( $56 \%$ vs. $20 \% ; p=0.006)$ was significantly higher in the non-survivor group in our study. These findings have been reported by several studies [25] and the same trends were observed by Maaloum et al. with more patients requiring RRT (50\% vs, $15 \%$; $p=0.05$ ) or mechanical ventilation $(88 \%$ vs. $76 \% ; p=0.66)$ in the nonsurvivor group [24].

The literature is conflicted with respect to determine age as an independent risk factor on survival in elderly patients. Martin-Loeches et al. reported in their prospective multicenter study that septic patients aged 80 and over have a higher hospital mortality compared to patients younger than 80 [14]. However, Flaatten et al. could show that the Clinical Frailty Scale is inversely associated with the 30-day survival. While $76 \%$ of the patients classified as "fit" were estimated to survive at 30 days following ICU admission only $59 \%$ of the patients who were classified as "frail" were estimated to survive the 30-day follow-up [26]. 
Table 3 Prosthetic Joint Infection locations are summarized in Table 3

\begin{tabular}{ll}
\hline & $\begin{array}{l}n=57 \\
(\text { Mean } \pm \text { SD) } \\
\mathrm{n}(\%)\end{array}$ \\
\hline Hip & $41(71.9 \%)$ \\
Knee & $14(24.6 \%)$ \\
Hip and Knee & $2(3.5 \%)$ \\
Acute Infection (< 4 weeks) & $8(14 \%)$ \\
Chronic Infection (> 4 weeks) & $49(86 \%)$ \\
Number of surgical interventions since prothesis & $2.19 \pm 3.2$ \\
implantation & $(0.10)$ \\
\hline
\end{tabular}

Our results also suggest that age per se has a smaller impact on survival than other factors such as the CCI, SAPS II and RRT [26, 27].

We observed a significantly higher rate of patients transferred from another ICU ( $31 \%$ vs. $5 \% ; p=0.006)$ in the non-survivor group. This might be explained by a delayed therapy, especially in cases when the septic prothesis has not been removed in the transferring hospital or the adequate antibiotic treatment has not been started. We did not analyze the surgical treatment delay in patients who have been transferred to our ICU. Nevertheless, previous studies have shown that an immediate treatment within the first hours is associated with a reduction in hospital mortality in very old patients [14, 28].

Treatment of very elderly patients admitted to the ICU is complex and represents an ongoing challenge for surgeons and intensive care specialists. Even though systematic ICU admissions of elderly patients failed to reduce the mortality [29] an appropriate and systematic approach with precise predictions models are needed for this patient group [30, 31].

\section{Limitations}

This study has several limitations: It is an observational, non-comperative, single-center cohort study in a retrospective setting, and therefore we may have missed data points and there is potential for bias or residual confounding from factors we did not measure. The available literature is lacking in comparible

Table 4 Reasons for ICU admission are summarized in Table 4

\begin{tabular}{ll}
\hline & $\begin{array}{l}n=57 \\
(\text { Mean } \pm \text { SD) } \\
\mathrm{n}(\%)\end{array}$ \\
\hline Planned surgical intervention & $20(50.9 \%)$ \\
Medical Reason & $12(21.1 \%)$ \\
Unplanned surgical intervention & $16(28.1 \%)$ \\
Transfer from other ICU & $7(12.3 \%)$ \\
\hline
\end{tabular}

Table 5 Factors associated with poor mortality are summarized in Table 5

\begin{tabular}{|c|c|c|c|}
\hline & survivor & $\begin{array}{l}\text { non- } \\
\text { survivor }\end{array}$ & $\boldsymbol{p}$-value \\
\hline cases & $\begin{array}{l}41 \\
(71.9 \%)\end{array}$ & $\begin{array}{l}16 \\
(28.1 \%)\end{array}$ & \\
\hline Male gender & $\begin{array}{l}17 \\
(41 \%)\end{array}$ & $7(43 \%)$ & 0.87 \\
\hline Age, mean \pm SD & $\begin{array}{l}83.8 \pm \\
3.3\end{array}$ & $\begin{array}{l}86.2 \pm \\
5.2\end{array}$ & 0.1 \\
\hline Days on ICU, mean $\pm S D$ & $\begin{array}{l}10.1 \pm \\
11.1\end{array}$ & $\begin{array}{l}16.4 \pm \\
16.5\end{array}$ & 0.1 \\
\hline $\mathrm{CCl}^{*}$, mean $\pm \mathrm{SD}$ & $\begin{array}{l}2.73 \pm \\
2.04\end{array}$ & $\begin{array}{l}4.94 \pm \\
2.14\end{array}$ & 0.02 \\
\hline ASA score*, mean \pm SD & $\begin{array}{l}3.12 \pm \\
0.51\end{array}$ & $\begin{array}{l}3.00 \pm \\
0.73\end{array}$ & 0.54 \\
\hline SAPS $\|$ Score*, mean \pm SD & $\begin{array}{l}24.32 \pm \\
15.3\end{array}$ & $\begin{array}{l}34.06 \pm \\
14.8\end{array}$ & 0.03 \\
\hline $\mathrm{BMI}^{*}$, mean $\pm \mathrm{SD}$ & $\begin{array}{l}27.64 \pm \\
5.65\end{array}$ & $\begin{array}{l}24.06 \pm \\
2.55\end{array}$ & 0.03 \\
\hline Invasive ventilation, no(\%) & $8(20 \%)$ & $9(56 \%)$ & 0.006 \\
\hline Hours of ventilation, median \pm SD & $\begin{array}{l}28.1 \pm \\
41.9\end{array}$ & $\begin{array}{l}132.7 \pm \\
143.3\end{array}$ & 0.06 \\
\hline $\mathrm{RRT}^{*}$, no (\%) & $\begin{array}{l}2 \\
(4.9 \%)\end{array}$ & $8(50 \%)$ & $\begin{array}{l}< \\
0.001\end{array}$ \\
\hline $\begin{array}{l}\text { Number of surgical intervention during } \\
\text { hospital stay }\end{array}$ & $\begin{array}{l}2.3 \pm \\
1.9\end{array}$ & $\begin{array}{l}1.9 \pm \\
1.5\end{array}$ & 0.3 \\
\hline $\begin{array}{l}\text { Number of surgical intervention since } \\
\text { prosthesis implantation, mean } \pm S D\end{array}$ & $\begin{array}{l}2.8 \pm \\
3.5\end{array}$ & $\begin{array}{l}0.7 \pm \\
1.1\end{array}$ & 0.3 \\
\hline \multicolumn{4}{|l|}{ Localisation of PJ } \\
\hline Hip, no (\%) & $\begin{array}{l}28 \\
(68 \%)\end{array}$ & $\begin{array}{l}13 \\
(81 \%)\end{array}$ & 0.5 \\
\hline Knee, no (\%) & $\begin{array}{l}11 \\
(27 \%)\end{array}$ & $3(19 \%)$ & 0.5 \\
\hline Knee and Hip & $2(5 \%)$ & 0 & 0.5 \\
\hline Transferred from other ICU & $2(5 \%)$ & $5(31 \%)$ & 0.006 \\
\hline
\end{tabular}

\section{Reason for ICU admission}

Unplanned surgical

Unplanned medical

Scheduled surgical

$\begin{array}{lll}14 & 2 & 0.26\end{array}$

$\begin{array}{lll}8 & 4 & 0.26\end{array}$

Acute Infection

$19 \quad 10 \quad 0.26$

$\begin{array}{lll}7 & 1 & 0.29\end{array}$

* CCI Charlson Comorbidity Index; ASA American Society of Anaesthesiologists Score; BMI Body mass index; RRT Renal replacement therapy; SAPS II Simplified Acute Physiology Score II; PJI Periprosthetic joint infection

studies. Furthermore, there is a huge variety in the definition of acute and periprosthetic joint infections in the literature ranging from 4 up to 12 weeks. Therefore, conclusion based on our results should be drawn carefully.

However, this study is the first ever to report and analyze risk factors on survival in very elderly patients with PJI admitted to the ICU. More studies are warranted to better understand risk factors on mortality 
Table 6 Multivariate logistic regression for mortality is shown in Table 6*

\begin{tabular}{llll}
\hline & $\mathrm{OR}^{*}$ & $95 \%-\mathrm{Cl}$ & $\boldsymbol{p}$-value \\
\hline CCI* $^{*}$ & 1.5 & $1.004-2.12$ & $\mathbf{0 . 0 4 8}$ \\
Invasive ventilation & 9.6 & $1.28-71.9$ & $\mathbf{0 . 0 2 8}$ \\
RRT $^{*}$ & 15.4 & $1.69-140.85$ & $\mathbf{0 . 0 1 5}$ \\
Transferred from other ICU & 2.5 & $0.39-15.47$ & $\mathbf{0 . 3 3 9}$
\end{tabular}

* OR Odds ratio; Cl Confidence interval; CCl Charlson Comorbidity Index; RRT Renal replacement therapy

rates and offer these special patients the best possible treatment.

\section{Conclusion}

Very elderly patients with PJI who needs to be admitted to the ICU are at risk to suffer from a poor outcome. Several risk factors including a chronic infection, high SAPS II Score, high CCI, invasive ventilation and RRT might be associated with a poor outcome. Health care providers should inform these patients accordingly. The literature is lacking in studies analyzing this particular group of patients and further research is needed. Prospective multi-center cohort trials and comparative clinical trials represent a key area of opportunity for future studies.

\section{Abbreviations}

AAOS: American academy of orthopedic surgeons; ASA: American society of anaesthesiologists score; CCl: Charlson comorbidity index; EBJIS: European bone and joint infection society; ICU: Intensive care unit; IMC: Intermediate care unit; MSIS: Musculoskeletal infection society; NNIS: National nosocomial infections surveillance; OR: Odds ratio; PJl: Periprosthetic joint infection; RRT: Renal replacement therapy; SAPS II: Simplified acute physiology score II; THR: Total hip replacement; TKR: Total knee replacement

\section{Acknowledgments}

Not Applicable.

\section{Authors' contributions}

Study concept: UH, CW, EY, TAS. Study design: EY, AP, HB, SF. Data acquisition: UH, AP. Data analysis and interpretation: EY, UH, AP, CW, HB, TAS. Statistical analysis: UH, AP, EY. Manuscript editing: EY, HB, SF. Manuscript review: UH, CW, TAS. All authors approved the final manuscript.

\section{Funding}

We acknowledge support by the DFG Open Access Publication Funds of the Ruhr-Universität Bochum.

\section{Availability of data and materials}

The data used and analyzed during the current study are available in anonymized form from the corresponding author on reasonable request.

\section{Ethics approval and consent to participate}

The study has been approved by the local Ethical Committee of the RuhrUniversity Bochum (No. of approval 18-6260-BR). Due to the retrospective nature of this study there was no need for consent to participate.

\section{Consent for publication}

Not applicable.

\section{Competing interests}

The authors declare that they have no competing interests.

\section{Author details}

'Department of General and Trauma Surgery, BG University Hospital Bergmannsheil, Ruhr University Bochum, Bürkle-de-la-Camp-Platz 1, 44789 Bochum, Germany. ${ }^{2}$ Medical Faculty of the University Duisburg-Essen, Essen, Germany.

Received: 4 March 2020 Accepted: 5 May 2020

Published online: 15 May 2020

\section{References}

1. Kiadaliri AA, et al. High and rising burden of hip and knee osteoarthritis in the Nordic region, 1990-2015. Acta Orthop. 2018;89(2):177-83.

2. Wallace IJ, et al. Knee osteoarthritis has doubled in prevalence since the mid-20th century. Proc Natl Acad Sci U S A. 2017;114(35):9332-6.

3. Maradit Kremers $\mathrm{H}$, et al. Prevalence of Total hip and knee replacement in the United States. J Bone Joint Surg Am. 2015;97(17):1386-97.

4. Oleske DM, et al. Electronic health databases for epidemiological research on joint replacements: considerations when making cross-national comparisons. Ann Epidemiol. 2014;24(9):660-5.

5. Kurtz S, et al. Projections of primary and revision hip and knee arthroplasty in the United States from 2005 to 2030. J Bone Joint Surg Am. 2007;89(4): $780-5$.

6. Kong $L$, et al. Risk factors for periprosthetic joint infection following primary total hip or knee arthroplasty: a meta-analysis. Int Wound J. 2017;14(3):52936.

7. Darouiche RO. Device-associated infections: a macroproblem that starts with microadherence. Clin Infect Dis. 2001;33(9):1567-72.

8. Parvizi J, et al. New definition for periprosthetic joint infection: from the workgroup of the musculoskeletal infection society. Clin Orthop Relat Res. 2011:469(11):2992-4.

9. Parvizi J, et al. The 2018 definition of periprosthetic hip and knee infection: an evidence-based and validated criteria. J Arthroplasty. 2018;33(5):13091314.e2.

10. Zimmerli W, Trampuz A, Ochsner PE. Prosthetic-joint infections. N Engl J Med. 2004:351(16):1645-54.

11. Trampuz A, Zimmerli W. Prosthetic joint infections: update in diagnosis and treatment. Swiss Med Wkly. 2005;135(17-18):243-51.

12. Alp $E$, et al. Incidence and economic burden of prosthetic joint infections in a university hospital: a report from a middle-income country. J Infect Public Health. 2016;9(4):494-8.

13. Haenle $\mathrm{M}$, et al. Economic impact of infected total knee arthroplasty. ScientificWorldJournal. 2012;2012:196515.

14. Martin-Loeches I, et al. Risk factors for mortality in elderly and very elderly critically ill patients with sepsis: a prospective, observational, multicenter cohort study. Ann Intensive Care. 2019;9(1):26.

15. Nielsson MS, et al. Mortality in elderly ICU patients: a cohort study. Acta Anaesthesiol Scand. 2014;58(1):19-26.

16. Li C, Renz N, Trampuz A. Management of Periprosthetic joint infection. Hip Pelvis. 2018;30(3):138-46.

17. Ochsner, P., et al., Infections of the musculoskeletal system : basic principles, prevention, diagnosis and treatment. 2014: Grandvaux Swiss orthopaedics in-house-publisher 2014

18. Le Gall JR, Lemeshow S, Saulnier F. A new simplified acute physiology score (SAPS II) based on a European/north American multicenter study. JAMA 1993;270(24):2957-63.

19. Keats AS. The ASA classification of physical status--a recapitulation. Anesthesiology. 1978;49(4):233-6.

20. Charlson M, et al. Validation of a combined comorbidity index. J Clin Epidemiol. 1994:47(11):1245-51.

21. Kunutsor SK, et al. Systematic review of risk prediction scores for surgical site infection or periprosthetic joint infection following joint arthroplasty. Epidemiol Infect. 2017;145(9):1738-49.

22. Haddad FS, Ngu A, Negus JJ. Prosthetic joint infections and cost analysis? Adv Exp Med Biol. 2017;971:93-100

23. Zhu Y, et al. Risk factors for periprosthetic joint infection after total joint arthroplasty: a systematic review and meta-analysis. J Hosp Infect. 2015; 89(2):82-9.

24. Maaloum Y, et al. Clinical spectrum and outcome of critically ill patients suffering from prosthetic joint infections. Infection. 2013;41(2):493-501.

25. Lai CC, et al. The outcomes and prognostic factors of patients requiring prolonged mechanical ventilation. Sci Rep. 2016;6:28034. 
26. Flaatten $\mathrm{H}$, et al. The impact of frailty on ICU and 30-day mortality and the level of care in very elderly patients ( $\geq 80$ years). Intensive Care Med. 2017; 43(12):1820-8.

27. Boumendil $\mathrm{A}$, et al. Variability of intensive care admission decisions for the very elderly. PLoS One. 2012;7(4):e34387.

28. Ferrer $\mathrm{R}$, et al. Empiric antibiotic treatment reduces mortality in severe sepsis and septic shock from the first hour: results from a guideline-based performance improvement program. Crit Care Med. 2014;42(8):1749-55.

29. Venkatesan P. Mortality in elderly patients with a systematic ICU admission programme. Lancet Respir Med. 2017;5(12):928.

30. Flaatten $\mathrm{H}$, et al. The status of intensive care medicine research and a future agenda for very old patients in the ICU. Intensive Care Med. 2017;43(9): 1319-28.

31. Kizilarslanoglu MC, et al. Is frailty a prognostic factor for critically ill elderly patients? Aging Clin Exp Res. 2017;29(2):247-55.

\section{Publisher's Note}

Springer Nature remains neutral with regard to jurisdictional claims in published maps and institutional affiliations.

Ready to submit your research? Choose BMC and benefit from:

- fast, convenient online submission

- thorough peer review by experienced researchers in your field

- rapid publication on acceptance

- support for research data, including large and complex data types

- gold Open Access which fosters wider collaboration and increased citations

- maximum visibility for your research: over $100 \mathrm{M}$ website views per year

At BMC, research is always in progress.

Learn more biomedcentral.com/submissions 